\title{
A framework of intelligent bidding system (iBS) of registration number for road Transport Department
}

\begin{abstract}
Online bidding is known by several names, including electronic reverse bid auctions, reverse auctions or simply e-Auctions. Online bidding and auction system has been growing rapidly and extensively in Malaysia. It's become an increasingly popular method for transacting business, especially over the Internet. Online auction systems such as eBay and Lelong.com are the most visited and favorite's website by the users. This study will come out with a framework of bidding system where the registration number of new registered vehicle can be bid in a computerized environment. The framework is designed to be a simple and easy to use the system. It provides you with real-time information during the bidding so that you can check the current price for the registration number and use it as a reference when you submit or revise your bid. With this system, it could help users to obtain a number plate through an unsealed or open bidding process to own and drive a car. An agent will notify the winner by sending an email. With the features like bid notification, it will help the user to know the status of their bids.
\end{abstract}

Keyword: Agent; E-auction; Intelligent bidding system; Online auction systems; Web-based system 